\title{
Analysis and modeling of harmonic distortions in consumer's distribution networks, containing a powerful non-linear load
}

\author{
Rakhmanov N.R. ${ }^{1}$, Kurbatsky V.G. ${ }^{2}$, Guliyev H.B. ${ }^{1}$, Tomin N.V. ${ }^{2}$, Rakhmanov R.N. ${ }^{1}$ \\ ${ }^{1}$ Azerbaijan Scientific-Research and Designed-Prospecting Institute of Power Engineering, Baku, Azerbaijan \\ ${ }^{2}$ Melentyev Energy Systems Institute Siberian Branch of the Russian Academy of Sciences, Irkutsk, Russian
}

\begin{abstract}
The paper proposes to simulate a random variability of the nonlinear load in the form of probabilistic characteristics of the amplitudes of harmonic components of powers. The influence of the variability of distribution of amplitude values of the power harmonics on the load flow in the network, power losses and maximum power transmission in lines is studied. The results of design experiments for one of distribution networks of Azerbaijan power system, feeding the non-linear load, are given.
\end{abstract}

\section{Introduction}

In modern power grids, due to the wide use of pulse technique in the power consumer control, along with the improvement of operation efficiency, the proportion of distortion from harmonic currents in the network from these control devices increases. The increase of harmonics leads to the voltage curve distortion and additionallosses. The deterioration of the power quality has a negative impact on the quality of product [1-3].

At present methods of estimation of harmonic distortions in distribution systems from different types of nonlinear loads are developed, in which it is supposed that the amplitude of power spectrum components of harmonic currents remains unchanged during the process of operation of consumers of non-linear loads (NL). The methodology of iterative decomposition on frequency components of NL currents is proposed in $[1,2]$. Distribution network up to the general connection point is calculated in the frequency range, while the power supply network of consumers is represented as a whole in the time interval. At that, the power (currents) of the power supply network of consumers is modeled using statistical methods. The analysis of probability of power changes of sources of harmonic distortions and assessment of interrelation between distortions in the power supply network and distribution networks is performed in [4-6]. In addition, in the same paper, the degree of influence of the voltage in the network on the harmonic distortions from each individual NL is estimated.

In this paper the analysis of an harmonicity of current and voltage in the distribution network, generated by random power changes of consumed NL, is performed. Arc steel furnaces (ASF) and power converters AC/DC installed for the connection of distributed generation system with an external system are considered as the nonlinear load. In addition, the problem of adaptive
NL modeling using machine learning (ML) algorithms for the impact assessment of parallel connection of harmonic filters is considered.

\section{Adaptive NL modeling for the har- monic filter connection impact as- sessment}

Since the use of harmonic filter reduces the harmonic components of currents (HCC), such a device also changes the harmonic components of voltages $(\mathrm{HCV})$ at the filter connection point [7]. Therefore, the filter connection will change the HCC NL. Usually, the presence of the filter reduces the voltage distortion, to which the NL responds with the increase of HCC. Such effect of positive feedback, called "harmonic amplification" [8], leads to the fact that the filter size calculated at the design stage becomes insufficient for the full-fledged reduction of HCC generated by NL. In turn, this can lead to damages of equipment of the non-linear consumer, for example, failure of ASF.

Theoretically, active harmonic filters (AHF) automatically adapt to load conditions. Based on the estimation of "harmonic amplification" during the AHF selection, the "harmonic amplification factor" parameter is used, which is often defined as the ratio of the nominal values of the total nonlinear distortions coefficient (NDC), $K_{U}$ NL and actually measured. Depending on the load type, the requirements for the AFG installation, this factor can be accepted from 1.1 to 2 [9]. However, in practice, the choice of AFG parameters and the need for its connection is a non-trivial task, since often the neighboring loads and properties of NL are unknown.

To solve this problem, usually one resorts to the development of different models of the NL behavior, located below the connection point. Such models are rele-

Corresponding author: huseyngulu @ mail.ru 
vant before the design and installation of the filter. Significant success in this direction was achieved by using ML algorithms that allow for creating adaptive training models capable of approximation of various nonlinear functions $[7,10]$.

This paper proposes a method for NL modeling using the ML model, to input of which the HCV values, measured at the filter connection point and the load factor of the system are entered. The output values of the model are the current of the main harmonic, as well as the subsequent most significant high-frequency HCC. In this case, the problem is represented as a multiple nonlinear regression recovery between the $\mathrm{HCV}$ and HCC. To solve this problem, two ML algorithms were studied in this paper in detail: extreme learning machine (ELM) [11] and random forest model for multiple regression (RF) [12].

\section{Experimental measurements of the mode parameters and indices of power quality in the ASF connection mode}

Currently, there is a sufficient range of equipment for the purpose of measuring and recording of the PQ parameters. Among these one can mention the devices of Siemens, LEM, S\&I (UK), MARS and PARMA (Russia), instruments of Italian producers, etc. All these measuring devices are capable of monitoring and recording parameters of PQ in real time and comply with GOST-32144-2013 [13]. From this point of view, the Simeas Q measuring and recording device was chosen as satisfying the measurement objectives and taking into account that there is a significant amount of instrumentation and security equipment of Siemens company in the power grid.

Functional capabilities of the Simeas Q PQ meter are as follows: recording of electrical parameters for the analysis of electricity quality; ability to perform monitoring in single-phase networks, in 3- or 4-wire threephase circuits; recording of exceeding limit values; transmission of recorded values through various communication channels (RS-232, RS-485, PROFIBUSDP).

\section{Experimental analysis of harmonic distortions from NL}

\subsection{Experimental studies for HCV and HCC in the node with a powerful NL}

As an example of NL, which creates stochastic changes in voltage and power in the network, the arc steel and aluminum melting furnaces, receiving power from the Azerenerji system, are considered. The 2x50 MW steel furnace is located in Baku city and connected to the power grid through a high-voltage distribution network. The diagram of the power supply network and electrical connections of this point with other load nodes of the power grid are shown in Fig.1. ASF is considered as a NL in the studied network. The load variability probabilistic nature level is shown in Figure 2 in the form of
HCC amplitude dynamics curves in the ASF and HCV circuit (at the point of connection of the NL to the network in the operating melting mode). Change of NDC $\mathrm{HCV}$ at the connection point is shown in Fig. 3.

In the paper, based on the proposed method, the design and experimental studies on the assessment of the contribution of ASF operation mode to the voltage, current and power in the power supply network are performed. The spectral composition of the current and voltage at the general connection point of the steel plant was established experimentally on the basis of measurements carried out during the month. The average values of harmonic voltage and current are given in tables 1 and 2, respectively.

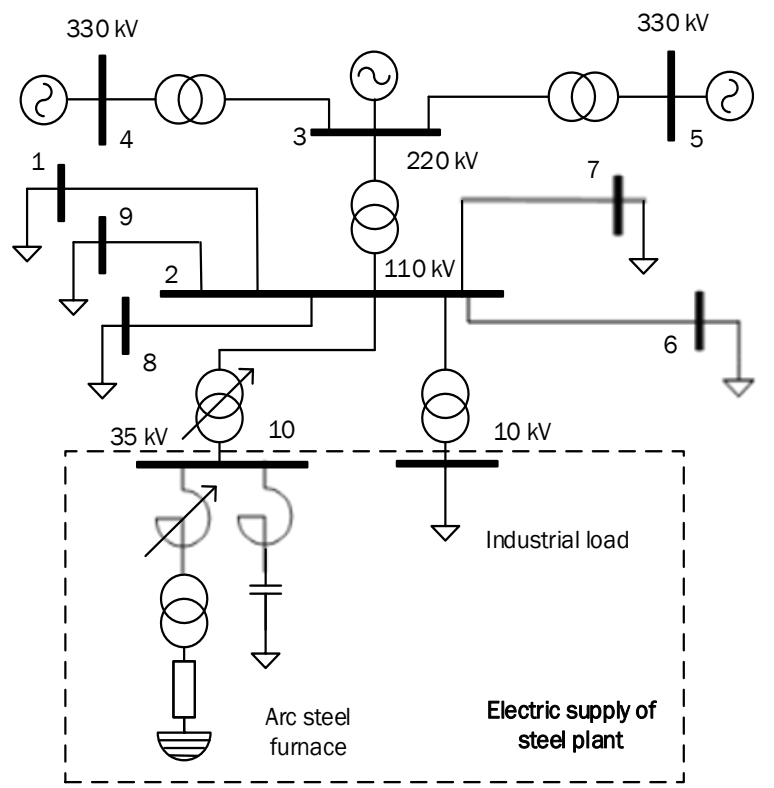

Fig.1. Diagram of electrical network supplying the Baku steel plant, taking into account the connections in the overall connection of ASF

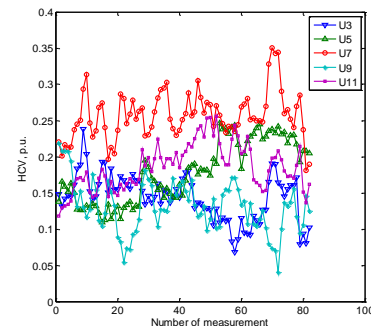

a)

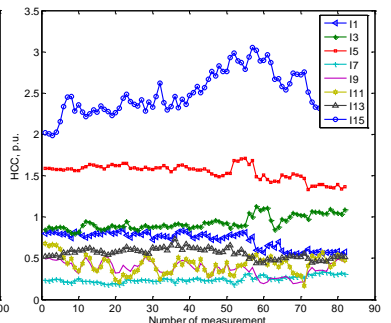

b)
Fig. 2. Change of HCV $\left(U_{n}\right)$ circuit in the ASF connection point (a) and significant $\mathrm{HCC}\left(I_{n}\right)$ in ASF (b)

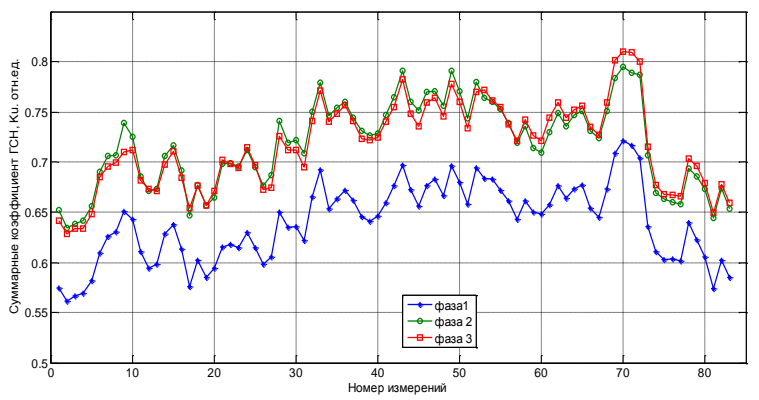

Fig. 3. Change of total ratio of $\mathrm{HCV}\left(K_{U}\right)$ at the connection point 
As can be seen from tables 1 and 2, the most significant frequencies in the voltage and current spectrum are harmonics 2, 3, 4, 5 and 7. Taking this into account, we calculate the distortion power flow in the electrical network of the power supply system generated by electric furnace of the steel plant. The electrical network parameter values for these higher harmonics are determined using known relationships for transformer, reactor and capacitive branches, respectively [1, 3].

Table 1. Voltage harmonics spectrum (\%).

\begin{tabular}{|c|c|c|c|}
\hline $\begin{array}{c}\text { Harmo- } \\
\text { nics }\end{array}$ & $\begin{array}{c}\text { Phase A } \\
\boldsymbol{U}=\mathbf{2 1 . 8} \mathbf{k V}\end{array}$ & $\begin{array}{c}\text { Phase B } \\
\boldsymbol{U}=\mathbf{2 1 . 1 6} \boldsymbol{k V}\end{array}$ & $\begin{array}{c}\text { Phase C } \\
\boldsymbol{U}=\mathbf{2 1 . 1 4} \mathbf{k V}\end{array}$ \\
\hline 2 & 0,19 & 0,6 & 0,63 \\
3 & 3,94 & 3,5 & 3,5 \\
4 & 0,16 & 0,42 & 0,2 \\
5 & 0,34 & 0,49 & 0,46 \\
6 & 0,12 & 0,1 & 0,21 \\
7 & 0,27 & 0,16 & 0,58 \\
8 & 0,18 & 0,04 & 0,36 \\
9 & 0,33 & 0,15 & 0,2 \\
10 & 0,3 & 0,1 & 0,17 \\
11 & 0,15 & 0,15 & 0,2 \\
12 & 0,09 & 0,27 & 0,16 \\
13 & 0,63 & 0,12 & 0,31 \\
14 & 0,21 & 0,2 & 0,24 \\
15 & 0,11 & 0,39 & 0,13 \\
\hline$K_{U}$ & 4,05 & 3,72 & 3,7 \\
\hline
\end{tabular}

Table 2. Current harmonics spectrum (\%).

\begin{tabular}{|c|c|c|c|}
\hline \multicolumn{4}{|c|}{$\begin{array}{c}\text { Phase A } \\
\text { Effective value } \\
I=161 \mathrm{~A}\end{array}$} \\
\hline 2 & 3,31 & 9 & 1,41 \\
\hline 3 & 11,62 & 10 & 1,70 \\
\hline 4 & 4,33 & 11 & 0,41 \\
\hline 5 & 4,63 & 12 & 0,82 \\
\hline 6 & 1,72 & 13 & 0,68 \\
\hline 7 & 1,48 & 14 & 0,25 \\
\hline 8 & 1,63 & 15 & 0,15 \\
\hline \multicolumn{4}{|c|}{$\begin{array}{c}\text { Phase C } \\
\text { Effective value } \\
I=134 \mathrm{~A}\end{array}$} \\
\hline 2 & 8,25 & 2 & 1,72 \\
\hline 3 & 10 & 3 & 1,32 \\
\hline 4 & 9,48 & 4 & 0,85 \\
\hline 5 & 10,60 & 5 & 1,43 \\
\hline 6 & 1,98 & 6 & 1,24 \\
\hline 7 & 3,58 & 7 & 0,02 \\
\hline 8 & 0,38 & 8 & 0,89 \\
\hline \multicolumn{4}{|c|}{$\begin{array}{c}\text { Phase C } \\
\text { Effective value } \\
I=152 A\end{array}$} \\
\hline 2 & 9,63 & 9 & 0,41 \\
\hline 3 & 9,13 & 10 & 2,11 \\
\hline 4 & 7,64 & 11 & 1,92 \\
\hline 5 & 10,20 & 12 & 1,38 \\
\hline 6 & 5,94 & 13 & 1,35 \\
\hline 7 & 3,56 & 14 & 1,16 \\
\hline 8 & 3,90 & 15 & 0,99 \\
\hline
\end{tabular}

In accordance with this, using the electrical network parameters data for the fundamental frequency (Table 4 ), the values of these parameters for the frequencies of the selected harmonics are determined. Harmonic distortion powers at the input buses of $110 \mathrm{kV}$ substation, supplying the steel plant (node 1 in Fig.1), and the distortion voltages for each phase are obtained as shown in Table 4.

Table 3. Total resistance of electric circuit of the furnace

\begin{tabular}{|c|c|}
\hline Harmonic No. & $\begin{array}{c}\text { Total resistance of electric circuit } \\
\text { of the furnace, } \mathbf{~ m O h m}\end{array}$ \\
\hline 2 & 10,26 \\
3 & 15,39 \\
4 & 20,52 \\
5 & 25,6 \\
7 & 35,91 \\
\hline
\end{tabular}

Table 4. Harmonic distortion powers and voltages

\begin{tabular}{|c|c|c|}
\hline Phase & $\begin{array}{c}\text { Distortion power } \\
(\mathbf{k V A})\end{array}$ & $\begin{array}{c}\text { Distortion } \\
\text { voltage (V)\% }\end{array}$ \\
\hline A & 18,75 & $841 / 4$ \\
B & 20,59 & $779 / 3,7$ \\
C & 23,59 & $768 / 3,6$ \\
\hline
\end{tabular}

For the determination of the distortion power the following formula is used [15]:

$$
D=\overline{S^{2}+P^{2}+Q^{2}}
$$

where $S$ - total power determined as follows:

$$
S=\overline{n_{m=1} U_{n}^{2} \cdot{ }_{n=1}^{n_{m}} I_{n}^{2}}
$$

$U_{n}$ and $I_{n}$ - voltage and current harmonics respectively.

The total power of harmonic distortions is $64 \mathrm{kVA}$, which is $0.5 \%$ of the power of steady-state mode of the electric furnace $-13000 \mathrm{kVA}$. The energy of this power is imposed on the external network and is consumed in it in the form of losses in its elements and in the elements of nodal loads.

The amount of this energy for the period of one melting (in our case is about 2 hours) is $64 \cdot 0.9 \cdot 2=$ $115 \mathrm{kWt} \cdot h$. At $10-12$ meltings per day the harmonic distortion energy will be about $1380 \mathrm{kWh}$ or $\sim 41400$ $\mathrm{kW}$.h per month (accepted payable period for electricity consumed).

Designed distribution of this distortion energy in the electrical network is presented in Table 5. For the determination of the distortion energy the following formula is used [16]:

$$
\begin{aligned}
& W_{\sum, D, P}=\quad{ }_{n=2}^{40} W_{D, P, n}=\frac{T}{\pi} \quad{ }_{n=2}^{40} P_{n} \\
& W_{\sum, D, P}=\quad{ }_{n=2}^{40} W_{D, Q, n}=\frac{T}{\pi} \quad{ }_{n=2}^{40} Q_{n}
\end{aligned}
$$

where $W_{D, P, n}, W_{D, Q, n}$ - distortion energy active and reactive components respectively; $P_{n}, Q_{n}$-active and reactive powers of harmonic components.

In the process of calculation of the harmonic content in the electrical network the distortion levels are determined not only in terms of the amount of energy emission in the form of additional power flows and losses of electricity, but also in magnitude (energy), and the volt- 
ages represent a quantitative measure of the contribution of each nonlinear load node to the deterioration of the PQ in the network of power supply organization.

Table 5. Load flows of harmonic distortion energy in the external network

\begin{tabular}{|c|c|c|}
\hline $\begin{array}{c}\text { Branch } \\
\text { No. }\end{array}$ & $\begin{array}{c}\text { Active energy flow } \\
\text { (kW.h) }\end{array}$ & $\begin{array}{c}\text { Energy losses in } \\
\text { branches (kW.h) }\end{array}$ \\
\hline $1-2$ & 3400 & 76 \\
$2-3$ & 319,9 & 9,6 \\
$2-6$ & 883,6 & 35,3 \\
$2-7$ & 304,7 & 6,4 \\
$2-8$ & 1009,3 & 32,3 \\
$2-9$ & 285,6 & 9,1 \\
$2-10$ & 300,5 & 9,0 \\
$3-4$ & 137,5 & 2,9 \\
$3-5$ & 179,2 & 5,6 \\
\hline \multicolumn{2}{|c|}{ Total: } & 186,2 кW.h \\
\hline
\end{tabular}

\subsection{NL modeling on the basis of machine learn- ing models}

To create the ML models, the R software environment was used with attraction of "elmNN" and "MultivariateRandomForest" packages. The tested EML and RF models were trained on the basis of measurements received from SIMEAS $Q$ and had the following structure: 9 input parameters (voltage of the fundamental harmonic and HCV harmonics 3, 5, 7, 9, 11, 13, 15, 17) and 5 output values (fundamental harmonic current and HCC 3, 5, 7, 9 harmonics).

At that, the ELM model had one hidden layer with 10 neurons with sinusoidal activation function (Fig. 4). RF model used the following parameters: number of trees, $n_{\text {tree }}=5$; the number of features for the selection of splitting, $\mathrm{m}_{\text {feature }}=5$; minimum number of splitting objects $\min _{\text {leaf }}=5$. At the intermediate stages of the study, the Bayesian ANN proposed for this task in [7] was also trained and tested. However, in our study of NL ASF modeling this neural network showed a low accuracy.

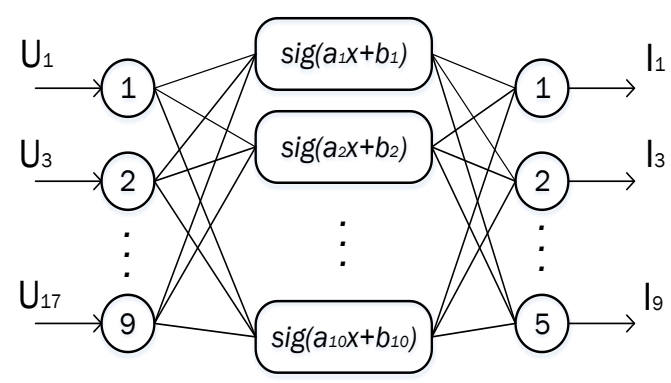

Fig. 4. Architecture of ELM used for the NL modeling
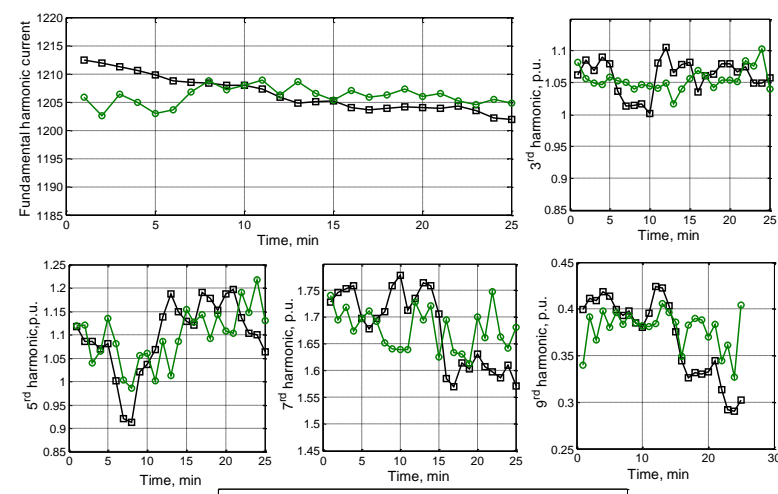

$\rightarrow$-Measurument (SIMEAS Q) $\rightarrow-$ Neural network modelling

Fig. 5. Results of NL modeling using EML model

The results of testing of the trained models are presented in Fig. 5 and in Table 6. Standard regression metrics were used to evaluate the effectiveness: mean absolute error (MAE) and root- mean-square error (RMSE).

Table 6. Results of testing of machine learning models for the HCC ASF predict.

\begin{tabular}{|l|l|l|l|l|}
\hline \multirow{2}{*}{ HCC } & \multicolumn{2}{|c|}{ ELM model } & \multicolumn{2}{c|}{ RF model } \\
\cline { 2 - 5 } & $M A E$ & $R M S E$ & $M A E$ & $R M S E$ \\
\hline $\begin{array}{c}\text { Fundamental } \\
\text { harmonic } \\
\text { current }\end{array}$ & 2.889 & 3.699 & 13.234 & 13.968 \\
\hline $3^{\text {rd }}$ harmonic & 0.028 & 0.031 & 0.023 & 0.028 \\
\hline $5^{\text {th }}$ harmonic & 0.056 & 0.068 & 0.065 & 0.083 \\
\hline $7^{\text {th }}$ harmonic & 0.059 & 0.072 & 0.069 & 0.082 \\
\hline $9^{\text {th }}$ harmonic & 0.031 & 0.040 & 0.042 & 0.051 \\
\hline
\end{tabular}

As can be seen from Table 6 , the best results are given by ELM, which, apparently, is determined by its best approximating properties in conditions of small samples [13]. However, it should be noted that a certain advantage of the RF model is that it does not require the analyzed data normalization. The choice of the optimal normalization method is a certain problem for neural network models, including the problem of NL behavior modeling [7].

As can be seen from Fig. 5, the obtained neural network model of the NL behavior on the example of ASF allows for the exact prediction of the $\mathrm{HCC}$ at different changes of $\mathrm{HCV}$, for example, during the harmonic filter connection.

\section{Conclusion}

On the basis of experimental studies carried out on the $110 \mathrm{kV}$ distribution network with the NL node in the form of a high-power ASF, the probability estimations of $\mathrm{HCV}$ in the nodes of the electric network from each harmonic are obtained and the total power distortion in the network is determined. The solution of the problem of adaptive NL modeling using ML algorithms to assess the effects of the inclusion of harmonic filters is presented.

This work was supported by the Science Development Foundation under the President of the Republic of AzerbaijanGrant № EIF-BGM-4-RFTF-1/2017-21/09/1 and RFBR according to the research project №18-51-06001. 


\section{References}

1. Rakhmanov R.N., .Mamedyarov O.S., Bayramaliyeva E. M..Identification of distortion of electrical network parameters with nonlinear loads. Collection of reports of International conference. Identification and control problems. IPU, M. (2002)

2. R.N. Rahmanov, I.Z. Islamov. Evaluation of the harmonic voltage distortion and its influence on power network insulation age. in Trans. of CIGRE conference on Power system insulation coordination, Abu-Dhabi, 298-302 (1998)

3. Zhezhelenko I. V., Korotkevich M. A. Electromagnetic compatibility in electrical networks. - Minsk: Vysheyshaya school, 197 (2012)

4. Van den Keybus J. Simulation of large numbers of non-linear loads in distribution systems / J. Van den Keybus et al., in IEEE Ninth Int.Conf.on Harmonics and Quality of Power, 2, (2000).

5. Rakhmanov R. N..Application of the neural network model to control the mode of electric power DSP // Energy problems.,No.1, 47-51 (2005)

6. Kovernikova L. I. Active powers of harmonics in the nodes of connection of nonlinear loads to the high voltage network / / Electricity, №3, 12-20 (2017)

7. Manuel L. Modelling harmonics drawn by nonlinear loads / L. Manuel, B. Josep, M. Juan, C. Montserrat and G. Eulalia, in $20159^{\text {th }}$ International Conference on Compatibility and Power Electronics (CPE), Costa da Caparica, 93-97 (2015)

8. Sainz, L. Harmonic Interaction Influence Due to Current Source Shunt Filters in Networks Supplying Nonlinear Loads / L. Sainz, J. Balcells // IEEE Transactions on Power Delivery,27,No.3, 1385 - 1393 (2012)
9. Schipman, K. Harmonic amplification demystified [Electronic resource] / K.Schipman. ABB United Kingdom, (2011) - available from: http://www04.abb.com/global/seitp/seitp202.nsf/0/d ba3255853945cfdc125783800573521?opendocume $\underline{\mathrm{nt}}$

10. Mazumdar J. RecurrentNeural Networks Trained With Backpropagation Through Time Algorithm to Estimate Nonlinear Load Harmonic Currents / J. Mazumdar and R. G. Harley // IEEE Transactions on Electronics, 55, No.9, 3484-3491 (2018)

11. Huang G.-B. Extreme Learning Machine for Regression and Multiclass Classification / G.-B. Huang et al. // IEEE Transactions on Systems, Man, and Cybernetics,Part B, 42, No.2, 513-529 (2011)

12. Segal, M. Multivariate random forests / M. Segal, and X. Yuanyuan // Wiley Interdisciplinary Reviews: Data Mining and Knowledge Discovery,1, No.1, 80-87 (2011)

13. Electric energy. Electromagnetic compatibility of technical means. Standards of quality of electric energy in power supply systems of general purpose. GOST 32144-2013-M.: Standardinform, 18 (2014)

14. Rakhmanov N. R., Kurbatsky V. G., Guliyev G. B., Tomin N. B. Short-term forecasting of power output of wind power plants to ensure the reliability of electrical networks / The 87-th Int. scientific seminar "Methodological issues of research of reliability of large energy systems", Minsk, Belarus, (2015)

15. Kopylov I. P. Definition of the dynamic energy indices at non-sinusoidal asymmetric voltage / I. P. Kopylov // Energetika, No.2, 31-38 (2001)

16. Farkhadzadeh E.M., Guliyev H.B. Bases of the Theory of Distortion in Electrical Circuits with Nonlinear Rower // Physics, №2, 29-33 (2003) 